\title{
Influence of Psychosocial work Environment on hydration status of construction workers in Southern Nigeria
}

\author{
Christopher Edet Ekpenyong* \\ Department of Physiology, University of Uyo, Nigeria
}

Submission: December 13, 2018; Published: January 11, 2019

*Corresponding author: Christopher Edet Ekpenyong, Department of Physiology, Faculty of Basic Medical Sciences, University of Uyo, Uyo, Nigeria

\begin{abstract}
Despite the increasing prevalence of psychosocial stressors at workplace, and the knowledge that they promote unhealthy behaviors associated with dehydration, little research has examined how these factors impact hydration status (HS) of workers. The aim of this study was to assess the effect of psychosocial stressors on HS of construction workers (CWs) in Nigeria. A cross-sectional study of 206 male CWs was performed at their site clinics and retained hospital using job content questionnaire scales. HS was determined by measuring urinary specific gravity and urinary osmolality. Prevalence of dehydration was $49.5 \%$ and was significantly higher among workers in the blue collar working $(\mathrm{P}=0.010)$, physically inactive $(\mathrm{P}=0.000)$, inadequate water intake $(\mathrm{P}=0.000)$, current alcohol drinking $(\mathrm{P}=0.000)$, age between $41-50$ years $(\mathrm{P}=0.033)$ and short sleep duration $(\mathrm{P}=0.022)$ groups. Higher odds for dehydration were found in the high demands $(\mathrm{OR}=2.000,95 \%$ C.I $=2.00-4.022, \mathrm{P}=0.000)$, low decision authority (OR=3.016, 95\% C.I=3.268-8.178, $\mathrm{P}=0.000)$ and low social support $(\mathrm{OR}=2.19,95 \%$ C.I $=2.02-$ $3.926, \mathrm{P}=0.002$ ) groups. Workers in the high strained job category had the highest odds (OR=3.44, C.I $=3.27-10.88, \mathrm{P}=0.0012$ ) for dehydration. Psychosocial workplace stressors are significant risk factors for dehydration and should be considered in any intervention to improve the effect of environmental factors on HS of CWs.
\end{abstract}

Keywords: Psychosocial stressors; Work environment; Dehydration; Health behaviors; Construction workers

\section{Introduction}

Dehydration describes a range of conditions associated with fluid deficit [1]. It is a growing public health burden due to its effect on health, economy, work performance and health related quality of life (HRQL) [2, 3]. Dehydration is an undesirable condition regardless of its magnitude [1] but frequently encountered. It is a well-known risk factor for morbidity and mortality such as renal injury, cardiovascular disease, poor oral hygiene, gastrointestinal disorders, poor skin integrity, poor work performance, cognitive dysfunction, urinary tract infection and malnutrition, and does not only constitutes a reason for hospital admission [4] but also increased the risk of death among patients admitted to hospital as medical emergency.

Many studies evaluating the impact of environmental factors on HS of CWs have mainly focused on the effects of physical work environment (temperature, humidity and wind velocity), while psychosocial work variables (job strain, job content, work organizational management, work pace, work load, work schedule and job control) have been largely ignored. Also, most policy discussions, labor laws, resources, and thresholdbased interventions remained devoted to the relatively narrow objectives of promoting physical work place safety such as the introduction of heat illness prevention campaign (water, rest and shade) [5], thermal guidelines for heat stroke prevention, occupational exposure limit values for heat stress, prediction models for heat disorders and labor laws/codes [6-11], while broader dimensions of the work place environment including adverse psychosocial workplace factors such as significant mental and emotional demands, poor leadership, lack of social support, economic insecurity, high job demands, long work hours, role conflicts, mobbing behavior, tension and burnout symptoms have not been sufficiently considered and therefore are increasingly prevalent [12].

Anecdotal evidence indicates that although these policy efforts have been introduced to tackle the adverse health effects of physical work environment, they are hardly implemented, especially in the setting of uncontrolled/poor psychosocial workplace factors, because, these two factors (physical and psychosocial) are known to exert a complementary and/or antagonizing effect on each other. They have the potentials to modify each other and either improve or worsen health outcomes. Studies by others have 
shown that failure to identify effect modifier can lead to misinterpretation of exposure-disease relationships and inefficiencies including incorrect targeting in developing intervention. Despite the long-recognized and important health effects of poor psychosocial working conditions and poor HS of workers in the construction industry, we are not aware of any study that has been done to evaluate the effect of psychosocial work exposures on HS of workers in the construction industry thereby leaving a significant gap in the existing research literature. The aim of the present study was to bridge this gap by assessing the effect of psychosocial work exposures on HS of CWs in southern Nigeria.

\section{Subjects and Methods}

Two hundred and eighty-three male workers from three construction sites (located within the same geographic area, and with no significant differences in environmental/physical factors) were examined at two site clinics and one retained hospital. of the number, two hundred and six qualified to participate and completed the psychosocial questionnaire between January 2017 and March 2018. Participation was voluntary; however, qualification for participation included the following; age between 18 and 65 years, male construction worker, defined as one who works at the construction site with his hands, skilled or unskilled. Included in this group were the manual laborers, migrant workers and the working man. Exclusion criteria were as follows; inadequate response to questionnaire, decline participation, newly employed staff ( $<1$ year), presence of debilitating illness, age outside the study age ( $<18>65$ years), sickle cell disease, renal disease, diabetes mellitus, diabetes insipidus, hypertension and being on medication for the treatment for any of these conditions. Also, subjects with missing demand-control items were excluded. All participants who met the inclusion criteria gave written informed consent, and the management of the construction sites granted approval, while the Institutional Research and Ethics Committee approved the study protocol.

Two survey instruments were used to assess the effect of psychosocial stress on HS of participants. These included a semistructured questionnaire adapted from previous studies on the effect of psychosocial stress on health behaviors associated dehydration $[13,14]$. The questionnaire comprised two sections (A and B). Section A contained questions aimed at exploring sociodemographic profile (age, gender, income level, employment status, and lifestyle habits (sleeping duration, smoking status, dietary habits, physical activity status, and alcohol drinking habits). Age was stratified into 3 groups 18-30, 31-40 and > 40 years. Income level was categorized into 2 groups N10, 000-N20, 000 and $>$ N20, 000/month.

Sleeping duration/status was determined by asking the following questions; "how many hours do you sleep per night"? "Do you usually wake up in the middle of the night?" this question excluded daytime naps. Based on duration of night sleep, participants were classified into three groups; short sleep $\leq 6 \mathrm{hrs}$ / night, normal sleep 7-8hrs/night and long sleep, > $8 \mathrm{hrs} /$ night
[15]. Cigarette smoking habits was stratified into current, ex-and non-smoking. Current smokers were those who smoked up to the day of the survey, ex-smokers were defined as those who had stopped smoking up to six months prior to the study period, while non-smokers were those who never smoke.

A $24 \mathrm{~h}$ dietary recall questionnaire was used to obtain information on participants' dietary habits and water intake. They were asked to state the daily composition of their diets/ fluids intake in terms of quantity, and frequency of consumption. Participants with moderate intake of balanced diets 2-3 times per day with a substantial amount of fruits and vegetables added to it were grouped as having good dietary habits, while those with excessive consumption of unbalanced diets were grouped as having poor dietary habits. Participants who took up to $3.7 \mathrm{~L} / 24 \mathrm{~h}$ of water (according to Institute of Medicine) were considered as adequate water intake, while those that too less were considered as inadequate water intake.

Based on the number of cups and frequency of intake, low water intake was considered if the participant takes less than 16 cups of water in $24 \mathrm{~h}$ or consumed water for $<3$ times $/ 24 \mathrm{~h}$. Greater than this amount was considered adequate water intake [16]. Physical activity level was assessed based on the 2010 US healthy people physical activity guidelines standard which recommends 150 minutes of moderate to severe intensity of aerobic exercise per week in bouts of 10 minutes or more for physically active adults ages between 18 and 64 years.

Based on alcohol intake, participants were grouped into current drinkers (those who drank up to $24 \mathrm{hrs}$ prior to study period), ex-drinkers (those who stopped drinking up to 6 months prior to the study period and non-drinkers (those who never drink alcohol). Employment status of participants was stratified into blue collar if manual laborer, migrant worker or the working man (skilled or unskilled) otherwise they were classified as whitecollar workers. The second part of the questionnaire contained 13 items concerning psychosocial work factors that were selected from the job content questionnaire which measured job control, job demands and social support. The job demands scale comprised 5 questions relating to job speed, job difficulty, intensity, time pressure and mental work load.

Four questions measured work control. "My job permits freedom of decision, acquisition and application of new ideas, is free from conflicting ideas from others, has task that are interrupted before they can be completed, or is characterized by repeated laying off and recruitment of workers". Four questions measured social support. Each response was categorized on a 5-point Likert Scale "completely agree" "partially agree", "neither agree nor disagree", "partially disagree", or "completely disagree". Each answer attracted a score range of 1-5 point, with 5-points representing the higher level of demand or control.

Points for the control demand dimensions were summed up and dichotomized at the median and combined into four groups; low strain (low demand and high control), high strain (high 
demand and low control), active (high demand and high control) and passive (low demand and low control). The reliability and internal consistency of the variables in this instrument have been reported previously [17].

\section{Assessment Measures}

The anthropometric index measured in the present study was body mass index (BMI) defined as the ratio of body weight in kilogram $(\mathrm{kg})$ divided by the square of height in meters Weight $(\mathrm{kg}) /$ Height $^{2}\left(\mathrm{~m}^{2}\right)$. Weight was measured with a portable weighing scale. Height was measured with a stadiometer. Participants were instructed to wear ligh weight clotting and no shoes. BMI was interpreted as underweight (BMI $\left.>18 \mathrm{~kg} / \mathrm{m}^{2}\right)$, normal weight (BM $18-24.9 \mathrm{~kg} / \mathrm{m}^{2}$ ), overweight (BMI $25-29.9 \mathrm{~kg} / \mathrm{m}^{2}$ ) and obese (BMI $\geq 30 \mathrm{~kg} / \mathrm{m}^{2}$ ).

The main outcome of this study was incident dehydration, defined as urinary specific gravity (USG) $>1.020 \mathrm{glml}$ and or urinary osmolality ( $\mu \mathrm{osm})$ (>831mosm $/ \mathrm{kg})$. However, HS of participants was stratified into euhydration (USG $=\leq 1.015$ ), marginal adequate hydration (USG: 1.016-1.020), hypo-hydration (USG = 1.021-1.025), severe hypo-hydration $(\mathrm{USG}=1.026-1.03)$ and clinical dehydration (USG=>1.030) based on the criteria used by the Australian pathology association. Hypo-hydration, severe hypo-hydration, and clinical dehydration were merged and referred to as dehydration.

The USG was measured using electronic handheld optical refractometer (ATAGO-105) using urine collected before commencement of work and at the close of work. The average of the 2 measurements was used as the experimental value.

\section{Statistical Analysis}

Frequency counts and percentages were used to analyze the demographic/lifestyle characteristics of the participants and results presented for dehydrated and non-dehydrated participants using cross tabulation. Associations between socio-demographic/ lifestyle variables, psychosocial stressors, (work strain, work demands, decision authority and social support) and dehydration were examined using chi-square test. The multivariate analysis was also performed using multiple logistic regression models (with and without adjustment for other covariates) to identify the significant risk factors of dehydration among the participants. Hence, odds ratios (ORs) and the corresponding 95\% confidence intervals (CIs) were estimated and $\mathrm{p}<0.05$ was considered statistically significant. Statistical analysis was performed using Statistical Package for Social Sciences (SPSS) version 22.0).

\section{Results}

This cross-sectional study conducted in three construction sites showed that of the 283 workers initially selected to participate in the survey, 206 responded and met the inclusion criteria. This number represents a response rate of $72.8 \%$. Among the participants, $49.5 \%$ were dehydrated (USG > 1.020) while $50.5 \%$ had normal HS (USG < 1.020). The socio-demographic variables (age, sleep duration, physical activity status, water intake, employment status and alcohol intake) were significantly different between the EU hydrated and dehydrated participants. Higher prevalence of dehydration was found among participants within the ages of 41-50 (38.2\%), who had short sleep duration (81.4\%), physically inactive (52.9\%), employed as blue-collar workers $(87.3 \%)$, currently drinking alcohol (47.1\%) and were not drinking enough water $(62.7 \%)$. Also, age of the respondents $(\mathrm{P}=0.033, \mathrm{P}<0.05)$, sleep duration $(\mathrm{P}=0.022, \mathrm{P}<0.05)$, physical activity status $(\mathrm{P}<0.001)$, water intake $(\mathrm{P}<0.001)$, alcohol intake $(\mathrm{P}<0.001)$ and employment status $(\mathrm{P}=0.010)$ were significantly $(\mathrm{P}<0.05)$ associated with dehydration. Results obtained for other socio-demographic variables failed to rich statistically significant level $(\mathrm{P}>0.05)$ (Table 1$)$.

Table1: Demographic and life-style characteristics of the study participants.

\begin{tabular}{|c|c|c|c|c|c|}
\hline Sociodemographic Variables & Total & Dehydration (102) & EU hydration (104) & $\mathrm{X}^{2}$ Value & P-value \\
\hline \multicolumn{6}{|c|}{ Age (Years) } \\
\hline $18-30$ & $64(31.1)$ & $26(25.5)$ & $38(36.5)$ & & \\
\hline $31-40$ & $80(38.8)$ & $37(36.3)$ & $43(41.3)$ & 6.81 & $0.033^{*}$ \\
\hline $41-50$ & $62(30.1)$ & $39(38.2)$ & $23(22.1)$ & & \\
\hline \multicolumn{6}{|c|}{ Sleep duration (per Night) } \\
\hline$<6 \mathrm{hr}$ & $151(73.3)$ & $83(81.4)$ & $68(65.4)$ & & \\
\hline $7-8 \mathrm{hr}$ & $34(16.5)$ & $10(9.8)$ & $24(23.1)$ & 7.67 & $0.022^{*}$ \\
\hline$>8 \mathrm{hr}$ & $21(10.2)$ & $9(8.8)$ & $12(11.5)$ & & \\
\hline \multicolumn{6}{|c|}{ Income level (Naira) } \\
\hline $10,000-20,000$ & $43(20.9)$ & $25(24.5)$ & $18(17.7)$ & & \\
\hline $21,000-30,000$ & $163(79.1)$ & $77(75.5)$ & $86(82.7)$ & 1.21 & 0.271 \\
\hline \multicolumn{6}{|c|}{ Smoking habits } \\
\hline Current smokers & $51(24.8)$ & $28(27.5)$ & $23(22.1)$ & & \\
\hline Non-smokers & $121(58.7)$ & $59(57.8)$ & $62(59.6)$ & 1.02 & 0.602 \\
\hline
\end{tabular}




\section{Psychology and Behavioral Science International Journal}

\begin{tabular}{|c|c|c|c|c|c|}
\hline Ex-smokers & $34(16.5)$ & $15(14.7)$ & $19(18.3)$ & & \\
\hline \multicolumn{6}{|c|}{ Dietary habits } \\
\hline Good & $81(39.3)$ & $33(32.4)$ & $48(46.2)$ & & \\
\hline Poor & $125(60.7)$ & $69(67.6)$ & $56(53.8)$ & 3.55 & 0.059 \\
\hline \multicolumn{6}{|c|}{ Physical activity $(\% \geq 150 \mathrm{~min} / \mathrm{wk})$} \\
\hline Active & $130(63.1)$ & $48(47.1)$ & $82(78.8)$ & & \\
\hline Inactive & $76(36.9)$ & $54(52.9)$ & $22(21.2)$ & 21 & $<0.0001^{* *}$ \\
\hline \multicolumn{6}{|c|}{ Obesity status $\left(\mathrm{kg} / \mathrm{m}^{2}\right)$} \\
\hline Normal & $169(82.0)$ & $78(76.5)$ & $91(87.5)$ & & \\
\hline Overweight / obese & $37(18.0)$ & $24(23.5)$ & $13(12.5)$ & 3.54 & 0.06 \\
\hline \multicolumn{6}{|c|}{ Employments status (\%) } \\
\hline White collar job & $31(15.0)$ & $13(12.7)$ & $18(17.3)$ & & \\
\hline Blue collar job & $175(85.0)$ & 89 (87.3) & $86(82.7)$ & 0.52 & 0.471 \\
\hline \multicolumn{6}{|c|}{ Water intake (ml/day) } \\
\hline Adequate & 109 (52.9) & 38 (37.3) & $71(68.3)$ & & \\
\hline Inadequate & $97(47.1)$ & $64(62.7)$ & $33(31.7 \%)$ & 18.66 & $<0.0001^{* *}$ \\
\hline \multicolumn{6}{|c|}{ Alcohol intake (g/day) } \\
\hline Current drinkers & $71(34.5)$ & $48(47.1)$ & $23(22.1)$ & & \\
\hline Non-drinkers & $83(40.3)$ & $26(25.5)$ & $57(54.8)$ & 20.67 & $<0.0001^{* *}$ \\
\hline Ex-drinkers & $52(40.3)$ & $28(27.4)$ & $24(23.1)$ & & \\
\hline
\end{tabular}

*significant at $5 \%(P<0.05)$.

** significant at $1 \%(\mathrm{P}<0.01)$.

The results of the association between psychosocial work variables and HS showed that job demands $(\mathrm{P}<0.001)$, decision authority $(\mathrm{P}<0.001)$ and social support $(\mathrm{P}=0.018)$ were significantly associated with dehydration with higher prevalence of dehydration found among those with high job demands

(53.8\%), low decision authority (74.0\%) and low social support (52.9\%) Table 2 . Work strain was also found to be significantly associated with dehydration $(\mathrm{P}=0.047)$ with high strain jobs $(44.7 \%)$ having higher prevalence of dehydration than those in other groups (Table 3).

Table 2: Relationship between psychosocial work components and hydration status of participants.

\begin{tabular}{|c|c|c|c|c|c|}
\hline $\begin{array}{l}\text { Psychosocial work } \\
\text { variables }\end{array}$ & Total & $\begin{array}{c}\text { Dehydration } n=102 \text { USG }=\geq \\
1.021\end{array}$ & EU hydration $n=104$ USG $=\leq 1.020$ & $\mathrm{X}^{2}$ Value & P-value \\
\hline \multicolumn{6}{|c|}{ Psychosocial demands } \\
\hline High & $122(59.2)$ & $74(72.5)$ & $48(46.2)$ & 13.78 & $<0.0001^{* *}$ \\
\hline Low & $84(40.8)$ & $28(27.5)$ & $56(53.8)$ & & \\
\hline \multicolumn{6}{|c|}{ Decision latitude } \\
\hline Low & $116(56.3)$ & $39(38.2)$ & $77(74.0)$ & 25.4 & $<0.0001^{* *}$ \\
\hline High & $90(43.7)$ & $63(61.8)$ & $27(26.0)$ & & \\
\hline \multicolumn{6}{|c|}{ Social support } \\
\hline Low & $91(44.2)$ & $36(35.3)$ & $55(52.9)$ & 5.77 & $0.016^{*}$ \\
\hline High & $115(55.8)$ & $66(64.7)$ & $49(47.1)$ & & \\
\hline
\end{tabular}

*significant at $5 \%(p<0.05)$.

**significant at $1 \%(p<0.01)$

Table 3: Relationship between work strain variables and hydration status of participants.

\begin{tabular}{|c|c|c|c|c|c|}
\hline Work strain Variables & Total & Dehydration & EU hydration & $\mathbf{X}^{2}$ Value & P-value \\
\hline Low strain workers & $26(16.0)$ & $12(12.8)$ & $14(20.3)$ & 7.97 & $0.047^{*}$ \\
\hline High strain workers & $59(36.2)$ & $42(44.7)$ & $17(24.6)$ & & \\
\hline
\end{tabular}




\section{Psychology and Behavioral Science International Journal}

\begin{tabular}{|c|l|l|l|l|}
\hline Active workers & $39(23.9)$ & $18(19.1)$ & $21(30.4)$ & \\
\hline Passive workers & $39(23.9)$ & $22(23.4)$ & $17(24.6)$ & \\
\hline
\end{tabular}

*Significant at $5 \%(P<0.05)$.

Results of multiple logistic regression analysis showed that job demands $(\mathrm{P}<0.0001)$, decision authority $(\mathrm{P}<0.001)$ and social support were significantly associated with dehydration with higher odds among those with high job demands (OR=2.009, C.I=2.009-4.022, $\mathrm{P}<0.0001$ ), low decision authority (OR=3.016, C.I=3.068-8.178, $\mathrm{P}<0.001)$ and low social support $(\mathrm{OR}=2.19$, C.I=2.02-3.926, $\mathrm{P}=0.002$ ). Table 4 shows that work strain was significantly $(\mathrm{P}<0.05)$ associated with dehydration with higher odds among participants exposed to high strain jobs (OR=3.44, C.I=3.27-10.88, $\mathrm{P}=0.0012)$, passive jobs $(\mathrm{OR}=2.88$, C.I=2.72-8.07, $\mathrm{P}=0.0016)$ and active jobs $(\mathrm{OR}=1.92$, C.I $=1.602-3.44, \mathrm{P}=0.049)$ than the low strain jobs.

Table 4: Multiple logistic regression showing the relationship between work strain level and risk of dehydration among participants.

\begin{tabular}{|c|c|c|c|}
\hline Work strain & OR & $\begin{array}{c}\mathbf{9 5 \%} \text { C.I of } \\
\text { OR }\end{array}$ & P-value \\
\hline Low strain & 1.00 (reference) & & \\
\hline High strain & 3.44 & $3.27-10.88$ & $0.0012^{*}$ \\
\hline Active work & 1.92 & $1.602-3.44$ & $0.049^{*}$ \\
\hline Passive work & 2.88 & $1.72-8.07$ & $0.0016^{* *}$ \\
\hline
\end{tabular}

**Significant at $1 \%(P<0.01)$.

\section{Discussion}

The results of this cross-sectional study of male CWs showed that poor psychosocial work environment is a significant risk factor for inadequate HS of participants. Evidence for this notion is twofold: first, dehydrated participants had higher frequency of psychosocial stress-induced unhealthy behaviors than those with normal hydration level, a finding that corroborates previous studies that demonstrated positive correlation between these unhealthy behaviors and risks of dehydration [16].

Second, participants with unfavourable psychosocial work profile had higher risk of dehydration than those who were not psychosocially disadvantaged. For instance, high strain jobs and passive jobs were associated with $>3$ times and $>2$ times more likelihood of being dehydrated than low strain jobs, while high job demands, low decision authority and low social support were significantly associated with 2 times, $>3$ times and $>2$ times respectively more likelihood of being dehydrated than others. The plausible mechanism(s) linking poor psychosocial work conditions and dehydration is not quite clear and literature evidence is scant on this relationship. However, the link between psychosocial stress and dehydration has at long last acquired a patho-physiologic explanation. Compelling evidences indicate that adverse psychosocial work conditions can directly or indirectly affect health. Indirectly, through the promotion of unhealthy behaviors $[18,19]$. Overindulgence in these behaviors as observed in psychosocially stressed individuals leads to dehydration.
The relevant unhealthy behaviors observed in the present study and known to affect HS [2], include poor eating/dietary habit, habitual alcohol consumption and smoking, physical inactivity, inadequate water intake, short sleep duration, excessive coffee consumption, overweight/obesity, and use of unprescribed medications. For instance, studies of both humans and experimental animals showed that high work strain is associated with changes in some behavioral parameters including poor eating/dietary habits (e.g., increased intake of high energy foods, saturated-fat, sugary snacks, low-fiber fruits, low water intake and low-vegetable diets) [20-22]. In other studies, poor dietary habits have been shown to relate directly with health outcomes including dehydration $[23,24]$.

At this point time, it should be noted that the effect of psychosocial stress on some health-related behaviors of dehydration is not consistent across studies, likely due to differences in race, type, intensity and duration of stress. For instance, using different animal models of psychosocial stress, many investigators have shown that chronic psychosocial stress can either increase or decrease the latency to feed consumption or water intake as well as body weight [25-33]. In a related study, Rostamkhani et al. [34] noted that while water intake remained unchanged, increased feed consumption and higher weight gain were observed in animals exposed to chronic psychosocial stress. Vidal et al. [33] showed that low social support increased latency to drink water, and according to a study by Abdel-Azza et al. [35], adverse psychosocial work profile caused increase intake of unhealthy foods in humans as a way of coping with stress.

Inadequate water intake in the present study also correlated with higher prevalence of dehydration among participants, supporting previous studies that showed that low water intake is a major risk factor for dehydration since water intake contributes a greater proportion of the total body fluid. The clinical significance of adequate water intake is enormous and contributes significantly to the overall HS of an individual. Besides thirst quenching effect, adequate water intake has inverse correlation with poor dietary habits [36], and other risk factors of dehydration including obesity.

We also identified higher prevalence of dehydration among participants who currently drink alcohol in the present study. We know from literature that alcohol consumption increases with exposure to stressful work environments, and that poor HS is a consequence of heavy/chronic alcohol consumption [37]. Studies by Romelsjo et al. [37-39] independently demonstrated positive and significant correlation between stressful working conditions and heavy and binge drinking of alcohol/smoking, however, mixed results have been reported in other studies $[13,40]$ likely due to un-observed individual heterogeneity.

The plausible explanations for stress-induced alcohol use/ smoking are twofold: first, as a form of compensatory/adaptive 
response to the effect of stress-induced physiological changes and associated changes in internal homeostasis, such as anti-anxiety or antidepressant agents $[13,41]$. Second, due to weakening of individual's self-control following prolonged psychosocial reactions [42,43]. Alcohol intake increased the odds for dehydration due to its diuretic effects especially when consumed in a significant amount ( $>4 \%$ ) [2]. Numerous epidemiological studies have demonstrated a strong and positive association between poor psychosocial work components and physical inactivity [44-48].

It is now known that individuals in high strain and passive jobs are specifically more likely to be physically inactive during their leisure time $[49,50]$. Meanwhile, physical inactivity is a known risk factor for dehydration [16]. Therefore, the finding of a higher frequency of dehydration among the physically inactive participants in the present study alongside with higher odds for dehydration among participants in the high strain and passive jobs suggest an apparent relationship between these poor psychosocial components (high strain and passive jobs) and risk of dehydration.

Understanding this relationship may permit developing an effective approach for early risk prediction for dehydration and associated diseases, particularly among workers in occupations characterized by high psychosocial stressors such as workers in the construction trade. Several studies have acknowledged the fact that construction industry operates in a highly psychosocially stressful and competitive environment and is organized in a project-based pattern where decisions are not centralized but are made by frontline personnel [51] with constant alteration in work force, work pace and complexity of work, leaving each construction worker to battle with psychosocial stress [52].

According to Malia and Bacerril [53] construction work is the most stressful profession after mining and policing. However, other studies failed to keep pace with this observation by showing no association between high strain and passive jobs and physical inactivity, probably due to effect modification by the individual unique biological characteristics (demographics, tolerance, and genetics). This could provide explanation for the fact that not all physically inactive or psychologically stressed workers in the present study were dehydrated. Also, the no effect observed in some studies may be due to inadequate power corollary of small sample size [54]. The physiological pathways connecting high strain and passive jobs and physical inactivity have been explained in studies by Karasek and Theorell [55] and Landsbergis et al. [56] who associated high-strain jobs with fatigue and greater need for recovery and leading to increase sedentary behavior; also, there is high likelihood of exhibiting a passive lifestyle by individuals with passive unchallenging jobs.

The effect of stressful work environment on health behaviors also influences the weight status of workers through the promotion of unhealthy dietary habits [21,57] and physical inactivity status [58]. Also, work strain, and in particular shift works and prolonged working hours disrupt sleep and normal metabolic activities $[59,60]$ and leading to abnormal weight gain and obesity [61]. One study showed that prolonged stressful work can lead to abnormal deposition of intra-abdominal fat [62].

Evidently, abnormal fat accumulation (overweight and obesity) is a recognized personal risk factor for dehydration [63]. This explains the higher prevalence of dehydration among obese participants than others, in the present study. Furthermore, the frequency of dehydration was higher among participants in the short sleep duration group as against those in other groups, supporting previous studies that linked chronic stressful jobs (shift work or excessive long work hours) with disruption of normal sleep duration $[61,60]$ as well as those that showed that short duration of sleep is associated with poor HS [64] probably due to disturbances in circadian rhythm-release of vasopressin when normal sleeping pattern is disrupted [64].

Besides exerting the above indirect effects, emerging evidence suggests that un-favorable psychosocial work conditions can also directly impact HS of workers by confounding/or aligning with physical factors to promote poor health status. For example, severe heat stress associated with climate change has been shown to impact negatively on the family, co-workers, and community psychosocial health/relationships including heat-related violence, homicide, suicide, physical assault, spouse abuse [65-67], conflict over resources, migration and dislocation, drug abuse, poor dietary habits, inadequate water intake, alcohol abuse and leading to dehydration.

Likewise, poor psychosocial work exposures can hinder the implementation of various threshold-based intervention strategies against the adverse effect of physical work environment. Physiologically, high strain jobs associated with high physical exertion could lead to a greater fluid loss and dehydration [2]. A systematic review by LaMontagne et al. [68] showed that occupational health interventions that integrate the effect of psychosocial work environment achieved a more effective outcome than those that neglect the effect of psychosocial work exposures. Accordingly, psychosocial interventions have proved useful in causing remission of psychosocial stress related disorders and prevent progression to chronic diseases [69].

\section{Conclusion}

Overall, from the results of the present study, we conclude that psychosocial workplace stressors are significant risk factors for poor HS of CWs. The found association can be explained by the effect of psychosocial stress-induced unhealthy behaviors. This observation has important policy implications/recommendations. First, for any initiative to effectively mitigate the adverse effect of environmental factors on HS of CWs, it needs to be multi-faceted and should focus on a complete work environment including psychosocial workplace stressors.

Besides tackling the impact of physical work environment, stringent measures directed either at changing the workers 
themselves through behavioral or educational programs such as programs to reduce unhealthy behaviors (e.g., improve dietary habits, reduce alcohol intake and smoking, promote physical activity, adequate water intake, sleep duration and proper weight control) or redesigning job to reduce workplace practices that contribute to workplace-induced stress [68]. For instance, centralization/uniformity of work policies including working hours, work flexibility, work load and job intensity. Also, introduction of social support programs for workers and programs to improve and strengthen the relationship between staff, management and co-workers.

Beyond the measures described here, effort should be made to identify the implicated workplace psychosocial stressors and actions directed at reducing them. However, care should be taken to avoid the selection/targeting of unfounded stressors to avoid waste of resources. Selection of stressors should be based on empirical evidence that shows the effect size (odds ratios). Stressors with larger effect size contribute more towards poor HS and should be given priority attention.

This study has some limitations that should be considered in the interpretation of the results including those associated with the cross-sectional nature of the study design; therefore, association results from this study should not be viewed as causal. Also, selfreported personal characteristics/health behaviors are prone to over, and under estimation. Furthermore, study population of only male CWs limits generalization of results. However, the strength of the study includes carefulness in the selection and characterization of study participants, while controlling for the confounding effects of the physical work environment.

\section{References}

1. Adan A (2012) Cognitive performance and dehydration. J Am Coll Nutr 31(2): 71-78.

2. Ekpenyong CE (2016) Risk of dehydration among construction workers in relation to work task and personal characteristics. Ital J. Occup Environ Hug 7(2):99-111.

3. HoldsworthJE (2012) The importance of human hydration: perceptions among health professional. Across Europe Nurt Bull 37(1): 16-24.

4. Warren JL, Bacon WE, Harris T, McBean AM, Foley DJ, et al. (1994) The burden and outcomes associated with dehydration among US elderly 1991. AM J Public Health 84 (8): 1265-1269.

5. Johnson RJ, Glaser J, Sánchez-Lozada LG (2014) Chronic kidney disease of unknown etiology: A disease related to global warming? MEDICC Rev 16(2): 79-80.

6. AIOH (2003) Heat stress standard \& documentation developed for use in the Australian environment. In: Ross Di Corleto, Gerry Coles, Ian Firth Tullamarine (Eds.), Vic: the Australian Institutes of Occupational Hygienists Inc, Australia.

7. Miller VS, Bates GP (2009) Hydration, Hydration, Hydration. Ann Occyp Hyg 1-3.

8. ACGIH (2009) Heat stress and heat strain. TLV. Physical agents ( $7^{\text {th }}$ edn.), documentation. American Conference of Governmental Industrial Hygienists, USA.

9. Abu Dhabi EHS (2012a) Center Code of practice EHSRI. Safety in the heat (Abu Dhabi EHSMS Regulatory frame work. COP 11.0) Abu Dhabi
Environment Health and Safety Center, UAE.

10. Abu Dhabi EHS (2012b) Center Technical guideline: safety in the heat (Abu Dhabi EHSMS regulatory frame work). Abu Dhabi Environment Health and Safety Center, UAE.

11.ACGIH (2013) TLVs and BEIs-based on the documentation of the thresholds limit values for chemical substances and physical agents and biological exposure indices. America Conference of Governmental Industrial Hygienists Cincinnati, USA.

12. Melia JL, Becerril M (2007) Psychosocial sources of stress and burnout in the construction sector: A structural equation model. Psicothema 19(4): 679-686.

13. Azagbe S, Sharaf MF (2011) The effect of job stress on smoking and alcohol consumption. Health economics review 1:15.

14. Miranda H, Gore RJ, Boyer J, Nobrega S, Laura P (2015) Health behavior and overweight in nursing home employees contribution of workplace stressor and implication for work site health promotion. The Scientific World Journal 1-10.

15. Consensus Conference Panel, Watson NF, Badr MS, Belenky G, Bliwise DL, et al. (2005) Joint consensus statement of the American Academy of sleep medicine and sleep research society on the recommended amount of sleep for a health. Adult: Methodology and Discussion 38(8): 1161-1183.

16. Ekpenyong CE, Akpan IA M (2017) High prevalence and associated risk factors of dehydration among college students: implications for health and academic performance. Int J Community Med Public Health 4(4): 2394-6040

17. deAraujo TM, Karasek R (2008) Validity and reliability of the Job content questionnaire in formal and informal jobs in Brazil. SJWEH supplements 6: 52-59.

18. Beikic KL, Landsbergis PA, Schnall PL, Baker D (2004) Is job Strain a major sources of cardiovascular diseases risk? Scand J Work Environ Health 30(2): 85-128.

19. Chandola T, Britton A, Brunner E, Hemingway H, Malik M, et al. (2008) Work stress and Coronary heart disease: what are the mechanisms? Eur Heart J 29(5): 640-648.

20. Wardle J, Steptoe A, Oliver G, Lipsey Z (2000) Stress dietary restraint and food intake. J Psychosom Res 48(2): 195-202.

21. Torres SJ, Nowson CA (2007) Relationship between stress, eating behavior, and obesity. Nutrition 23(11-12): 887-894.

22. O'conner DB, Jones F, Conner M, McMillan B, Ferguson E (2008) Effects of daily hassles and eating style on eating behavior. Health Psychol 27(1S): S20-S31.

23. Growth MV, Fagi S, Brondsted L (2001) Social determinates of dietary habits in Denmark. Eur J Clin Nutr 55(11): 959-966.

24. Darmon, N, Drewnowski A (2008) Does social class Predict diet quality? Am J Clin Nutr 87(5): 1170-1177.

25. Rostamkhani F, Zardooz H, Zahediasl S, Farrokhi B (2012) Comparison of the effect of acute and chronic psychological stress on metabolic features in rats. J Zhejiang Univ Sci B 13(11): 904-912.

26. Armario A, Lopez-Calderon A, Jolin T, Balasch J (1986) Response of anterior pituitary hormones to chronic stress. The specificity of adaptation. Neurosci Biobehav Rev 10(3): 245-250.

27. Macht M, Krebs H, Weyers P, Janke W (2001) Effect of stress on feeding behavior in rats: individual differences. Pers Indiv Differ 30(3): 463469.

28. Bernatova I, Key MP, Lucot JB, Morris M (2002) Circadian differences in stress-induced pressor reactivity in mice. Hypertension 40(5): 768773 . 


\section{Psychology and Behavioral Science International Journal}

29. Ricart-Jane D, Rodriguez-Sureda V, Benavides A, Peinado-Onsurbe J Lopez-Tejero MD, et al. (2002) Immobilization stress alters intermediate metabolism and circulating lipoproteins in the rat. Metabolism 51(7): 925-931.

30. Foster MT, Solomon MB, Huhman KL, Bartness TJ (2006). Social defeat increases food intake, body mass, and adiposity in Syrian hamsters. Am J Physiol Regul Integr Comp Physio 290(5): R1284-R1293.

31. Tabarin A, Diz-Chaves Y, Consoli D, Monsaingeon M, Bale TL, et al. (2007) Role of the corticotropinre leasing factor receptor type 2 in the control of food intake in mice: a meal pattern analysis. Eur J Neurosci 26(8): 2303-2314.

32. Dorfman M, Ramirez VD, Stener-Victorin E, Lara HE (2009) Chronicintermittent cold stress in rats induces selective ovarian insulin resistance. Biol Reprod 80(2): 264-271.

33. Vidal J, Buwalda B, Koolhaas JM (2011). Differential long-term effects of social stress during adolescence and anxiety in Wistar and wild type rats. Behar Process 87(2): 176-182.

34. Rostamkhani F, Zardooz H, Zahediasl S, Farrokhi B (2012) Comparison of the effects of acute and chronic psychological stress on metabolic features in rats. J Zhejiang Univ Sci B 13(11): 904-912.

35. Abdel-AM, EL-Aziz, Soad A Sharkawy, Yousseria E, Yousef (2014) Relationship between stress and eating habits among nursing students in Assiut. Med J Cairo Univ 82(2): 47-55.

36. Kant AK, Graubard BI (2010) Contributors of water intake in US children and adolescence: Association with dietary and meal characteristics-national Health and Nutrition. Examination survey 2005-2006. AM J Clin Nutr 92(4): 887-896.

37. San JB, Van DMH, Van OJA, Mackenbach JP, Garretsen HF (2000) Adverse working conditions and alcohol use in men and women. Alcohol Clin Exp Res 24(8): 1207-1213.

38. Romelsjo A, Hasin D, Hilton M, Hilton M, Boström G, et al. (1992) The relationship between stressful working conditions and high alcohol consumptions and high alcohol consumption and serve alcohol problems in an urban general population. Br J Addict 87(8): 11731183.

39. Kuper H, Marmost M (2003) Job strain, Job demand, decision latitude, and risk of coronary heart disease within the Whitehall II study. J Epidemiol Community Health 57(2): 147-152.

40. Siegrist J, Rodel A (2006) Work stress and health risk behavior. Scand J Work Environ Health 32(6): 473-481.

41. Mensch BS, Kandel DB (1998) Do Job condition influence the use of drug? Journal of Health and Social Behavior 29(2): 169-184.

42. Ayyagari P, Sindelar JL (2010) The impact of job stress on smoking and quitting: Evidence from the HRS. The BE Journal of Economic Analysis and Policy 10(1)

43. Murraven M, Baumeister RF (2000) Self-regulation and population of limited resources: Does self-control resemble a muscle? Psychological Bulletin 126(2): 247-259.

44. Kouvonen A, Kivimaki M, Elovainio M, Virtanen M, Linna A, et al. (2005) Job strain and leisure-time physical activity in female and male public sector employees. Preventive Medicine 41(2): 532-539.

45. Payne N, Jones F, Harris PR (2005) The impact of job strain on predictive validity of the theory of planned behavior: an investigation of exercise and healthy eating. Br J Health Psychol 10(Pt1): 115-131.

46. Wemme KM, Rosvall M (2005) Work related and non-work-related stress in relation to low leisure time physical activity in a Swedish population. J Epidemiology Community Health 59(5): 377-379.

47. Yang X, Telama R, Hirvensalo M, Hirvensalo M, Hintsanen M, et al. (2010) The benefits of sustained leisure-time physical activity on job strain. Occup Med (Lond) 60(5): 369-375.
48. Choi B, Schnall PL, Yang H, Yang H, Dobson M, et al. (2010) Psychological working conditions and active leisure-time physical activity in middle aged US workers. Int J Occup Med Environ Health 23(3): 239-253.

49. Kouvonen A, Vahtera J, Oksanen T, Pentti J, Väänänen AK, et al. (2013) "Chronic workplace stress and insufficient physical activity: a cohort study". Occup and Envi Medic 70(1): 3-8.

50. Fransson EI, Heikkila K, Nyberg ST, Zins M, Westerlund H, et al. (2012) Job strain as a risk factor from leisure- time physical inactivity: an individual participants meta-analysis of up to 170,000 men and women: the IPD-work consortium. Am J Epidemiol 176 (12): 10781089 .

51.Jia YA, Rowlinson S, Ciccarelli M (2016) Climatic and psychosocial risk of heat illness incidents on construction site. Appl Ergon 53(A): 25-35

52. Ekpenyong CE, Inyang UC (2014) Association between workers characteristics, workplace factors and work-related musculoskeletal disorders. A cross-sectional study of male construction workers in Nigeria. Int J Occup Safe Ergon (JOSE) 20(3): 447-462.

53. Malia JL, Bacerril M (2007) Psychosocial sources of stress and burnout in the construction sector: A structural equation model. Psicothema 19(4): 679-686.

54. Montagne AD (2012) Invited commentary: Job strain and Health Behaviors Developing a bigger picture. AM J Epidemiol, 176(12): 1090-1094.

55. Karasek R, Theorell T (1991) Healthy work. Stress, productivity and reconstruction of working life. NY: Basic Books Inc.66: 4, New York, USA

56. Landsbergis PA, Schnall PL, Dietz DK, Warren K, Pickering TG, et al. (1998) Job Strain and health behaviors: results of a prospects study. Am J Health Promot 12(4): 237-245.

57. Mouchacca J, Gavin R A, Ball K (2013) Associations between psychological stress, eating, physical activity, sedentary behaviors and body weight among women: a longitudinal study. BMC Public Health 13: 828 .

58. Stults-Kolehmainen JMA, Sinha R (2014) The effects of stress on physical activity and exercise. Sports Medicine 44(1): 81-121.

59. Bray MS, Young ME (2011) Regulation of fatty acid metabolism by cell autonomous circadian clocks: time to fatten up on information? J Biol Chem 286(14): 11883-11889.

60. Tucker P, Marqui'e JC, Folkard S, Ansiau D, Esquirol Y (2012) Shift work and metabolic dysfunction. Chronobiology International 29(5): 549-555.

61. Gildner TE, Liebert MA, Kowal P, Chatteriji S, Josh SJ (2014) Sleep duration, sleep quality, and obesity risk among older adults from six middle-income countries: findings from the study on global ageing and adult health (SAGE). Am J Hum Biol 26(6): 803-812.

62. Schulte PA, Wagner GR, Ostry A, Laura AB, Robert GC, et al. (2007) Work, Obesity and Occupational safety and health. American Journal of Public Health 97(3): 428-436

63. Ritz, P, Vol S, Berrut G, Tack I, Arnaud M J, et al. (2008) Influence of gender and body composition on hydration and body water space. Clin Nutr 27(5): 740-746.

64. Colwell CS (2010) Preventing dehydration during sleep. Nature Neuroscience 13: 403-404.

65. Basu R, Samet JM (2002) Relation between ambient temperature and mortality. A review of the epidemiological evidence: Epidemiologic Reviews 24(2):190-202.

66. Doherty TJ, Claytons S (2011) The psychological impacts of global climate change. Am Psychol 66(4): 265-276.

67. Anderson CA (2001) Heat and violence current direction in Psychological Science 10: 33-38. 
68. La Montagne AD, Keegel T, Louie AM, Ostry A, Landsbergis PA (2007) A systematic review of the job-stress intervention evaluation literature, 1990-2005. Inter J Occup Environ Health 13(3): 268-280.

(c) (i)

This work is licensed under Creative Commons Attribution 4.0 License DOI: 10.19080/PBSIJ.2019.10.555789
69. Schneiderman N, Ironson G, Scott D, Siegel (2005) Stress and health: psychological behavioral and biological determinants. Annu Rev 1: 607-628.

Your next submission with Juniper Publishers
will reach you the below assets
- Quality Editorial service
- Swift Peer Review
- Reprints availability
- E-prints Service
- Manuscript Podcast for convenient understanding
- Global attainment for your research
- Manuscript accessibility in different formats
( Pdf, E-pub, Full Text, Audio)
- Unceasing customer service
Track the below URL for one-step submission
https://juniperpublishers.com/online-submission.php

